\title{
Atraindo novos funcionários para empresas de alta performance: uma crítica às razões dos profissionais de recursos humanos
}

\author{
Attracting new employees for high performance companies: a critique to human resource \\ professionals' reasons
}

Filipe Augusto Silveira de Souza ${ }^{1}$

Ana Heloísa da Costa Lemos ${ }^{2}$

Flavia de Souza Costa Neves Cavazotte ${ }^{3}$

Teresa Rachel Jesus Malva ${ }^{4}$

\section{Resumo}

Os chamados sistemas de trabalho de alta performance refletem a necessidade de organizações fortalecerem o envolvimento do trabalhador para que este responda mais rapidamente às demandas por resultados. Apesar de as práticas de alta performance promoverem uma gradual intensificação no trabalho e o aumento do nível de stress dos trabalhadores, e, portanto, restringirem a qualidade de vida e o bem-estar no trabalho, empresas de alta performance exercem grande poder de atração nos profissionais qualificados, o que enseja a indagação sobre os mecanismos que promovem essa atratividade. Para investigar esta questão, este estudo se debruça sobre os discursos proferidos por profissionais que atuam na área de recursos humanos de empresas de alta performance atuantes no Brasil. A pesquisa foi realizada por meio de entrevistas em profundidade com esses profissionais, com perguntas amplas sobre as atividades de recrutamento e seleção de funcionários. Os argumentos e motivos que permeiam os discursos desses profissionais foram analisados à luz do repertório conceitual da Teoria Crítica, particularmente o debate sobre as racionalidades que orientam a ação social. O exame dos discursos aponta para uma comunicação instrumentalmente orientada e para a distorção sistemática do processo comunicativo no interior das organizações, em detrimento do equilíbrio entre vida e trabalho e do bem-estar individual e interpessoal.

Palavras-Chave: Intensificação do trabalho. Racionalidade. Teoria crítica. Distorção comunicativa.

\section{Abstract}

The so-called high performance systems reflect the organizations' need to strengthen worker involvement in order to respond more quickly to demands for results. Despite the fact that high performance practices promote work

Artigo submetido em 24 de setembro de 2013 e aceito para publicação em 10 de outubro de 2014.

DOI: http://dx.doi.org/10.1590/1679-395111500

1 Doutorando em administração pela PUC-Rio. Endereço: IAG/PUC-Rio. Rua Marquês de São Vicente, 225, Gávea, CEP 22451-900, Rio de Janeiro - RJ, Brasil. E-mail: filipe.a.souza@globo.com

2 Doutora em sociologia pelo IUPERJ (atual IESP/UERJ); Professora adjunta da PUC-Rio. Endereço: IAG/PUC-Rio. Rua Marquês de São Vicente, 225, Gávea, CEP 22451-900, Rio de Janeiro - RJ, Brasil. E-mail: aheloisa@iag.puc-rio.br

3 Ph.D. em administração pela Virginia Commonwealth University; Professora adjunta da PUC-Rio. Endereço: IAG/PUC-Rio. Rua Marquês de São Vicente, 225, Gávea, CEP 22451-900, Rio de Janeiro - RJ, Brasil. E-mail: flavia.cavazotte@iag.puc-rio.br

4 Mestre em administração pela PUC-Rio. Endereço: IAG/PUC-Rio. Rua Marquês de São Vicente, 225, Gávea, CEP 22451-900, Rio de Janeiro - RJ, Brasil. E-mail: rachel.malva@ancar.com.br 
intensification and increasing stress levels, and thus restrict quality of life and well-being at work, high performance companies tend to appeal to a large number of qualified professionals; which gives rise to the question about the mechanisms that promote such attractiveness. In order to investigate this issue, this study focuses on the discourse of human resources professionals in high-performance companies operating in Brazil. The research was conducted through in-depth interviews with these professionals, based on broad questions about their recruitment and selection practices. The arguments and motives that permeate the professionals' discourse were analyzed in light of the conceptual repertoire of Critical Theory, particularly the debate about the rationalities that guide social action. The examination of the discourses points to an instrumentally oriented communication and a systematic distortion of the communicative process within organizations, at the expense of work-life balance and individual and interpersonal well-being.

Keywords: Job intensification. Rationality. Critical theory. Communicative distortion.

\section{Introdução}

Nos últimos anos, as empresas têm se estruturado para garantir que seus processos de produção propiciem o aumento da produtividade e melhores resultados financeiros. No Brasil, à semelhança de outros países, esse processo também desencadeou a reestruturação da forma de produção, cujos impactos se fazem sentir nas organizações, nas ocupações, nos sindicatos e na própria força de trabalho (BASTOS e BORGESANDRADE, 2002). Tais mudanças impactam diretamente na forma como os indivíduos estabelecem suas relações de trabalho com as organizações; e o êxito destas iniciativas depende, em grande parte, do envolvimento subjetivo do trabalhador.

Preocupadas com a melhoria de posicionamento no mercado, as empresas adotam estratégias de gestão que afetam a forma como o trabalho é organizado e controlado e colocam em prática políticas de recursos humanos que incentivam o alto envolvimento do funcionário (GREEN, 2001; 2004). É nesse contexto que ganham proeminência os sistemas de trabalho de alta performance (BUTLER, FELSTEAD, ASHTON et al., 2004), que refletem a necessidade de as organizações fortalecerem o envolvimento dos trabalhadores no processo produtivo, capacitando-os para a tomada de decisão e, consequentemente, para que respondam mais rapidamente às demandas do mercado (HUSELID, 1995; APPELBAUM, BAILEY e BERG, 2000; MACKY e BOXALL, 2008).

$\mathrm{Na}$ busca por atrair profissionais mais qualificados, as empresas investem em processos de recrutamento mais estruturados e no desenvolvimento de novas competências dentro das equipes, que passam a trabalhar de forma flexível e polivalente. Estas práticas de recursos humanos, somadas a um sistema de remuneração baseado em resultados, representam a base do sistema de trabalho de alta performace (MACKY e BOXALL, 2008). Diferentes autores sugerem que a adoção de práticas de trabalho de alta performance beneficiam tanto a organização quanto o indivíduo (HARTOG e VERBURG, 2004; HUGHES, 2008). As organizações se beneficiariam por terem em suas equipes trabalhadores mais motivados, comprometidos, responsáveis e leais, portanto, menos propensos a deixarem a empresa e a se ausentarem do trabalho (HUSELID, 1995). O funcionário, por sua vez, teria maior autonomia e controle sobre suas tarefas e decisões, veria mais sentido em seu próprio trabalho, sentindo-se valorizado, estimulado e recompensando (APPELBAUM, BAILEY e BERG, 2000).

Vale ressaltar que, apesar destes supostos benefícios, as práticas de alta performance tendem a gerar uma gradual intensificação no trabalho e no nível de stress dos trabalhadores, tanto pelo aumento dos níveis de responsabilidade quanto pela inevitável redução das equipes que a introdução de sistemas de alto desempenho envolve (HEWLETT e LUCE, 2006; SPARHAM e SUNG, 2007). Na busca pela competitividade, muitas organizações impõem ritmos de trabalho excessivos diante dos padrões até então usuais, aumentam o nível de exigência da contribuição individual e pedem uma dedicação incondicional do profissional aos resultados esperados pela empresa (GREEN, 2000; DAL ROSSO, 2008). 
Destaca-se, ainda, que o processo de intensificação do trabalho se dá em paralelo à crescente preocupação da sociedade com questões relativas à qualidade de vida e ao equilíbrio entre trabalho e vida pessoal. Diversos estudos analisam a questão de uma perspectiva crítica (WHITE, HILL, MCGOVERN et al, 2003; MACKY e BOXAL, 2008). Se por um lado, o aumento da intensidade do trabalho está vinculado a melhores resultados em termos de produtividade para as empresas e a maiores salários para os trabalhadores (GREEN, 2000), por outro, também resulta em exaustão física e mental (GREEN e MCINTOSH, 2001). Todavia, atualmente, mesmo tendo aumentado a preocupação dos trabalhadores com questões sobre qualidade de vida e bem-estar no trabalho, muitas empresas adotam o discurso da alta performance, o que tende a se refletir em maior intensificação do trabalho. A despeito da extensão da jornada de trabalho e da maior pressão exercida sobre os trabalhadores, essas empresas tendem a ser cobiçadas por um contingente expressivo de profissionais qualificados, que disputam vagas em processos seletivos concorridos e rigorosos.

O paradoxo entre as demandas por maior qualidade de vida no trabalho, de um lado, e a valorização da alta performance por empresas e trabalhadores, por outro, enseja diversos questionamentos. O que levaria os trabalhadores a escolherem empresas de alta performance para trabalhar? Que promessas são feitas por estas empresas para atrair e reter seus funcionários?

Essa última questão motivou este trabalho, cujo objetivo final consistiu em identificar, tendo como referência os discursos de profissionais que atuam na área de recursos humanos de empresas de alta performance, quais argumentos são proferidos no intuito de atrair novos quadros para essas organizações. Com vistas a analisar criticamente esses discursos, buscou-se identificar, nos relatos obtidos, a presença de elementos constitutivos da razão instrumental, razão esta que molda a ideologia dominante da sociedade industrial (GRIMES, 1992). Desta forma, o repertório conceitual elaborado nos marcos da Teoria Crítica, em especial o debate acerca das racionalidades que orientam a ação social, serviu de referência conceitual para a análise empreendida.

Para apresentar os resultados deste estudo, o presente artigo está estruturado em seis seções, incluindo esta introdução. A segunda seção apresenta o referencial teórico que identifica os Sistemas de Trabalho de Alta Performance e a Teoria Crítica, com ênfase na Teoria da Ação Comunicativa, que embasa conceitualmente a análise; a terceira, a metodologia utilizada, a quarta seção apresenta os resultados e, na última, são expostas as considerações finais.

\section{Referencial Teórico}

\section{Os sistemas de trabalho de alta performance}

Em um contexto marcado pela competitividade global, os sistemas de trabalho de alta performance vêm alcançando proeminência, sendo utilizados como recurso pelas organizações para maximizar o envolvimento dos empregados com o seu trabalho, bem como o seu compromisso com a organização, na expectativa de que isso melhore o desempenho organizacional (RAMSAY, SCHOLARIOS e HARLEY, 2000; KEHOE e WRIGHT, 2013; BÖCKERMAN, BRYSON e LMAKUNNAS, 2011).

Os sistemas de trabalho de alta performance (HPWS) são descritos como um conjunto de práticas de gestão distintas, mas interligadas, desenhadas para aumentar as habilidades, o comprometimento e a produtividade do funcionário, alavancando o seu desempenho e o da empresa (DATTA, GUTHRIE e WRIGHT, 2005; CHI e LIN, 2011; LEE e BANG, 2012). Estas práticas incluem procedimentos de recrutamento e seleção complexos e rigorosos, remuneração baseada em desempenho, amplo treinamento dos funcionários, estímulo ao trabalho em equipe (APPELBAUM, BAILEY e BERG, 2000; MACKY e BOXALL, 2008), metodologias de organização do trabalho envolvendo equipes multifuncionais, job rotation (HUSELID, 1995; HARTOG e VERBURG, 2004), desenho de tarefas e descrição de cargos menos rígidos, redução dos níveis hierárquicos e aumento da autonomia (HUGHES, 2008). 
Em uma visão otimista, autores como Appelbaum, Bailey e Berg (2000), Hartog (2004), Hughes (2008), Bashir, Jianqiao, Ghazanfar et al. (2012), Swarnalatha e Prasanna (2013) afirmam que essa nova organização do trabalho representa ganhos tanto para o empregado quanto para a empresa. Ao se analisarem as bases do sistema de alta performance, que englobam o foco no aumento das habilidades, da motivação e da autonomia dos funcionários, entende-se o mecanismo pelo qual estas práticas beneficiam as empresas tendo o comprometimento dos funcionários com a organização como mediador para os resultados alcançados. Funcionários que se identificam e se comprometem com os objetivos da organização tendem a aceitar a necessidade de dedicar esforços para cumprir os prazos mais curtos impostos à consecução destes objetivos (GREEN, 2000).

Para o trabalhador, os benefícios de trabalhar em empresas que adotam o sistema de alta performance refletem-se em salários maiores e satisfação com o trabalho, além de maior autonomia sobre as tarefas de trabalho e a forma de realizá-las. Em suma, pode-se dizer que os funcionários teriam suas necessidades atendidas pelas oportunidades que as práticas de alta performance proporcionam e responderiam a esses ganhos com um comportamento proativo e demonstração de lealdade aos seus empregadores (APPELBAUM, BAILEY e BERG, 2000; RAMSAY, SCHOLARIOS e HARLEY, 2000).

Macky e Boxall (2008), todavia, reforçam que enquanto há uma suposição quase natural de que as práticas voltadas para incentivar o envolvimento dos funcionários são vantajosas tanto para organização quanto para seus empregados, há algumas questões críticas que devem ser levadas em consideração. Mesmo apresentando benefícios para a empresa e para o funcionário, existem consequências negativas na adoção de sistemas de trabalho de alta performance (WHITE, HILL, MCGOVERN et al., 2003).

Práticas de trabalho que mobilizam o envolvimento dos funcionários estimulam um comportamento discricionário, levando-os a trabalhar mais (MACKY e BOXALL, 2008). Este nível exacerbado de envolvimento estimulado pelas políticas de recursos humanos facilita a intensificação do trabalho (GREEN, 2001; 2004) e, de acordo com Böckerman, Bryson e Lmakunnas (2011), também promove o aumento do absenteísmo. White, Hill, Mcgovern et al. (2003) destacam que, na busca por funcionários mais envolvidos e que se esforcem mais para alcançar as metas organizacionais, os sistemas de alta performance podem causar um impacto negativo na vida pessoal destes trabalhadores, pela exigência de mais dedicação, o que se traduz, muitas vezes, em mais horas trabalhadas. Os trabalhadores submetidos a estes sistemas sofreriam níveis mais altos de stress (ALLAN, O'DONNELL e PEETZ, 1999; GREEN e MCINTOSH, 2001) e ansiedade (WOOD e MENEZES, 2011) como consequência do aumento de responsabilidade, da maior autonomia, do incremento da participação dos trabalhadores na tomada de decisão e da intensificação do trabalho (CAÑIBANO, 2011). As organizações utilizam a força de trabalho de forma flexível e intensiva, impondo ritmos de trabalho por vezes considerados excessivos em relação aos padrões habituais, aumentando o nível de exigência sobre a contribuição individual do profissional e demandando deste uma dedicação incondicional aos resultados esperados pela empresa (GREEN, 2000).

As jornadas de trabalho mais extensas (HULST, VELDHOVEN e BECKERS, 2006), a multifuncionalidade da força de trabalho e a exigência de resultados superiores em um mesmo intervalo de tempo caracterizam o processo de intensificação do trabalho (GREEN, 2000), resultante de pressões da gestão e de incentivos oferecidos pela empresa para o alcance de melhores resultados (GREEN e MCINTOSH, 2001). De acordo com Böckerman, Brysone Lmakunnas (2011), se a adoção de práticas de trabalho de alta performance é simplesmente um meio de intensificar o esforço do trabalhador, isso pode levar a uma maior incidência de doenças, lesões, ausências e stress. Wood, Van Veldhoven, Croon et al. (2012) relatam ainda que estas práticas podem estar associadas à insatisfação com o trabalho e à ansiedade, e, em casos extremos, podem levar o trabalhador a deixar a organização.

De forma conclusiva, cabe destacar que, apesar de alguns aspectos constitutivos da dinâmica de trabalho característica das empresas de alta performance virem sendo discutidos de forma crítica por vários autores, entende-se que essa abordagem pode ser aprofundada ao se mobilizar um referencial teórico como aquele 
elaborado nos marcos da Teoria Crítica, com especial ênfase na Teoria da Ação Comunicativa (HABERMAS, 2012a; 2012b). Esse referencial é o tema da seção subsequente.

\section{Teoria Crítica e a crise da modernidade}

A Teoria Crítica é uma corrente do pensamento sociológico cuja origem remonta à criação do Instituto de Pesquisa Social, no início da década de 20, em Frankfurt, que se dedica "a examinaro mercado e suas relações à luz da emancipação, que significa a busca da realização concreta da liberdade e da igualdade" (VIEIRA e CALDAS, 2006, p. 62).

A partir de releituras do marxismo, da psicanálise e do idealismo filosófico alemão, integradas a uma sociologia de base empírica, a Escola de Frankfurt ${ }^{5}$ encontrou-se tensionada entre potencialidades e contradições da modernidade e a sua superação pela via revolucionária (BURREL e MORGAN, 2005). Opondo-se aos fundamentos epistemológicos da teoria tradicional, a-histórica, acrítica, e supostamente neutra, a Teoria Crítica prima pelo compromisso com a mudança social (TENÓRIO, 1998) e pela contraposição à ideologia dominante na sociedade ocidental, bem como às instituições que a reproduzem.

Posteriormente, sob influência weberiana, a veia crítica voltou-se contra o processo de racionalização da sociedade ocidental, resultando em um inescapável mecanismo de reprodução social, alicerçado no conceito de indústria cultural (ADORNO e HORKHEIMER, 2004). Tal guinada coincide, especialmente, com a experiência do fascismo, interpretada como o nível máximo de manifestação da racionalidade instrumental, na qual a racionalidade iguala-se à irracionalidade (KELLNER, 1992; JAY, 2008).

Ao promover um modo de vida baseado em interesses egocêntricos, a racionalidade instrumental orienta-se unicamente a fins últimos ou, em outras palavras, ao êxito. Nos termos propostos por Adorno e Horkheimer (2004, p. 25), no âmbito desta racionalidade, “[...] as múltiplas afinidades entre os entes são recalcadas pela única relação entre o sujeito doador de sentido e o objeto sem sentido, entre o significado real e o portador ocasional de significado". O compartilhamento de significados operados outrora, via interação simbólica, cede lugar ao controle técnico da natureza e da sociedade (GUERREIRO RAMOS, 1981).

A racionalidade instrumental tem como elementos constitutivos: o cálculo, entendido como a projeção utilitária das consequências dos atos humanos; a ênfase nos fins, na forma de metas de natureza técnica, econômica ou política; e a maximização dos recursos ou busca da eficiência e eficácia máximas, desprovida de questionamento ético, no tratamento dos recursos disponíveis de natureza diversa. A esses elementos somam-se a valorização do sucesso e dos resultados, isto é, o alcance de padrões, estágios e situações considerados como vitoriosos em face de processos competitivos numa sociedade capitalista; o desempenho, ou seja, a performance individual superior assumida como um valor generalizado; a utilidade que implica preponderância da dimensão econômica como base das interações, igualmente assumida como um valor generalizado; a rentabilidade associada unicamente ao retorno econômico dos êxitos e dos resultados esperados; e, finalmente, a ênfase na estratégia interpessoal, entendida como a influência planejada sobre outrem, com base na antecipação das suas reações prováveis a determinados estímulos e ações, visando atingir seus pontos fracos (SERVA, 1997).

No campo da ciência das organizações, a Teoria Crítica emerge na década de 80 (BURREL, 1994), influenciando decisivamente os estudos organizacionais (STEFFY e GRIMES, 1986; GRIMES, 1992; FORESTER, 1994; CARR, 2000).

\footnotetext{
${ }^{5}$ Associa-se, neste artigo, a denominação Escola de Frankfurt à primeira geração da Teoria Crítica, uma vez que os trabalhos de Habermas, expoente da segunda geração foram desenvolvidos, majoritariamente, em Starnberg, onde atuou como diretor do Instituto Max Planck (KELLNER, 1992).
} 


\section{A racionalização do mundo da vida e seus desdobramentos na esfera organizacional}

Membro da segunda geração da Escola de Frankfurt, Jürgen Habermas partilha da crítica à racionalidade instrumental elaborada por Adorno e Horkheimer, em Dialética do Esclarecimento (2004). Diverge, no entanto, do diagnóstico proposto pelos referidos autores, ao criticar o fato de estes deslocarem e reificarem a razão instrumental "[...] a um ponto anterior ao início capitalista da modernidade, até o começo da humanização" (HABERMAS, 2012a, p. 630). Em outros termos, ao proporem a homogeneização da força motriz a orientar a razão e ações humanas, em bases instrumentais, os autores retratam um cenário desolador, não passível de mudança.

No entendimento de Habermas, o referido diagnóstico decorre do aprisionamento destes autores à tradição da filosofia ocidental ou, em outros termos, ao paradigma da filosofia do conhecimento. Ao propor o entendimento da racionalidade em novas bases, o autor ancora sua construção teórica na filosofia da linguagem:

Por 'racionalidade' entendemos, antes de tudo, a disposição dos sujeitos capazes de falar e de agir para adquirir e aplicar um saber falível [...]. A razão centrada no sujeito encontra sua medida nos critérios de verdade e êxito, que regulam as relações do sujeito que conhece e age segundo fins com o mundo de objetos ou estado de coisas possíveis. Em contrapartida, assim que concebemos o saber como algo mediado pela comunicação, a racionalidade encontra sua medida na capacidade de os participantes responsáveis da orientação orientarem-se pelas pretensões de validade que estão assentadas no reconhecimento intersubjetivo. A razão comunicativa encontra seus critérios nos procedimentos argumentativos de desempenho diretos ou indiretos das pretensões de verdade proposicional, justeza normativa, veracidade subjetiva e adequação estética. (HABERMAS, 2002, p. 437).

A guinada linguística abraçada pelo autor permite-lhe propor um conceito alternativo de sociedade que procura romper com o reducionismo culturalista tanto de base fenomenológica quanto sistêmica. Ao passo que no primeiro caso, a sociedade iguala-se ao mundo da vida, com demasiada ênfase na liberdade e na capacidade reflexiva dos atores individuais; no segundo, equipara-se à noção de sistema, na qual os atores são tratados como funcionalmente orientados e subjugados por determinações externas. Compreendendo o mundo da vida e o sistema, o conceito de sociedade proposto por Habermas (2012b), no âmbito da Teoria da Ação Comunicativa, é concebido em termos de uma teoria evolutiva da sociedade, com base nos conceitos de "[...] racionalização do mundo da vida e da intensificação da complexidade dos sistemas sociais" (HABERMAS, 2012b, p. 216), presentes, crescentemente, nos diferentes níveis evolutivos; das sociedades tribais às modernas.

A crescente racionalização do mundo da vida, associada a uma maior complexidade social decorrente do afrouxamento das normas sociais tradicionalmente presentes, enseja a necessidade de diferenciação em seu interior, do qual se emancipam os subsistemas político e econômico, normativamente e comunicativamente deslocados do mundo da vida (DOMINGUES, 2004). Diversamente do mundo da vida, linguisticamente mediado, os subsistemas econômico e político têm como mecanismos reguladores o dinheiro e o poder respectivamente (FREITAG, 1993). A intensificação do processo de diferenciação do mundo da vida acaba por resultar na autonomização dos subsistemas político e econômico, ainda que à custa da reificação de tais sistemas como fechados e autopoiéticos (DOMINGUES, 2004), a tal ponto que "[...] os imperativos [destes], libertos, detonam a capacidade hermenêutica do mundo da vida, instrumentalizando-o" (HABERMAS, 2012b, p. 281).

Ambos os processos de racionalização e dissociação são assumidos por Habermas como patologias da modernidade. O primeiro processo resulta da colonização crescente do mundo da vida pelos imperativos 
sistêmicos, fruto de ambos os processos de naturalização das leis do mercado e de normatização do Estado burocrático. Ao subjugar as economias domésticas, a economia de mercado atua de forma determinante na conformação de uma sociedade baseada no consumismo e individualismo desenfreados. Portanto, "[...] o rendimento e a competitividade se transformam em sua força configuradora" (HABERMAS, 2012b, p. 587).

Já o processo de dissociação, resultante da autonomização das esferas de produção material de bens (Economia) e do poder político (Estado) das interações cotidianas do mundo da vida, acarreta o controle assimétrico dos mecanismos de mercado e da política, concentrados nas mãos de uma minoria (FREITAG, 1993).

Nos estudos organizacionais encontram-se exemplos dos mecanismos de dominação político-econômica, com ênfase especial na distorção do processo comunicativo, que tem lugar quando "[...] ao menos o comportamento de um dos participantes está orientado ao êxito, e os demais são levados a continuar acreditando que todos estão cumprindo os pressupostos do agir comunicativo" (HABERMAS, 2012a, p. 573). Nos termos propostos por Forester (1994, p. 138):

Quando organizações ou órgãos do estado são estruturados de forma que seus membros não têm nenhum recurso garantido para verificar os requisitos de veracidade, legitimidade, sinceridade ou clareza feitos sobre eles pelas estruturas estabelecidas de autoridade e produção, podemos encontrar condições de dogmatismo ao invés de informação social, tirania ao invés de autoridade, manipulação ao invés de cooperação, e insanidade ao invés de sensibilidade.

No que tange às instituições políticas, destacam-se os trabalhos que versam sobre a temática da gestão social ${ }^{6}$ (TENÓRIO, 1998; FRANÇA FILHO, 2008; CANÇADO, TENÓRIO e PEREIRA, 2011). Estudos empíricos nesta seara englobam, entre outros aspectos, a avaliação da implantação de políticas públicas governamentais na forma de parcerias com a sociedade civil e com o mercado (LORENZO, 2012); da estruturação de fóruns estruturados pelo governo e/ou iniciativa privada, com a intenção manifesta da ampliação das potencialidades da democracia participativa (TOWNLEY, COOPER e OATES, 2003; TOPAL, 2009; VIZEU e BIN, 2008).

No campo econômico, os estudos voltam-se à distorção do processo comunicativo nas interações corporativas com os seus públicos externo e interno (FORESTER, 1994; VIZEU, 2005; 2009; VIZEU e CICMANEC, 2013), caso este em que se enquadra o presente artigo.

Ressalta-se, por fim, o papel central da cultura corporativa como elemento chave na manipulação discursiva na interação das organizações com os seus membros com o propósito de reforçar aspectos tanto simbólicos quanto materiais, centrais aos propósitos corporativos e previamente disseminados via colonização do mundo da vida, seja por intermédio do processo educativo, seja pelo processo de comunicação de massa.

De forma conclusiva, entende-se que esta perspectiva crítica permite que se evidenciem nos discursos proferidos no âmbito corporativo - objeto do presente estudo - elementos constitutivos da razão instrumental e que, por esse motivo, serviu de lente conceitual para a análise dos relatos proferidos pelos entrevistados.

\footnotetext{
${ }^{6}$ Aplica-se aqui uma definição mais ampla do conceito, nos termos propostos pelo Programa de Estudos em Gestão Social (PEGS). O termo gestão social é "[...] entendido como o processo gerencial dialógico onde a autoridade decisória é compartilhada entre os participantes da ação. $\mathrm{O}$ adjetivo social qualificando o substantivo gestão é percebido como o espaço privilegiado de relações sociais onde todos têm o direito à fala, sem nenhum tipo de coação" (TENÓRIO, 2008, p. 147-148, apud CANÇADO, TENÓRIO e PEREIRA, 2011).
} 


\section{Aspectos Metodológicos}

No que diz respeito à coleta dos dados, a pesquisa, de natureza qualitativa, foi realizada por meio de entrevistas presenciais feitas com oito profissionais atuantes nas áreas de recursos humanos de diferentes empresas privadas. Para selecionar estes indivíduos utilizou-se como critério o reconhecimento, por parte do mercado, de que as empresas nas quais estes profissionais trabalhavam eram organizações de alta performance. Esta escolha foi ratificada na entrevista, quando os entrevistados confirmaram esta caracterização. Os sujeitos entrevistados foram identificados por meio das redes de relacionamentos dos pesquisadores e de sugestões dos próprios entrevistados, que indicaram novos sujeitos para a pesquisa. $\mathrm{O}$ Quadro 1 sintetiza o perfil dos entrevistados:

Quadro 1

\section{Perfil dos entrevistados}

\begin{tabular}{|l|l|l|}
\hline \multicolumn{1}{|c|}{ Identificação } & \multicolumn{1}{|c|}{ Cargo } & \multicolumn{1}{c|}{ Segmento de Atuação } \\
\hline Entrevistado 1 & Gerente de RH & CONSTRUÇÃO \\
\hline Entrevistado 2 & $\begin{array}{l}\text { Estagiária de Recrutamento e } \\
\text { Seleção }\end{array}$ & CONSUMO \\
\hline Entrevistado 3 & Consultora de gestão & CONSULTORIA \\
\hline Entrevistado 4 & $\begin{array}{l}\text { Coordenadora de } \\
\text { Desenvolvimento }\end{array}$ & VAREJO \\
\hline Entrevistado 5 & Analista de RH Sr & CONSULTORIA \\
\hline Entrevistado 6 & Coordenadora de RH & TELECOMUNICAÇÕES \\
\hline Entrevistado 7 & Coordenadora de RH & CONSUMO \\
\hline Entrevistado 8 & Gerente de RH & HOTELARIA \\
\hline
\end{tabular}

Fonte: Elaborado pelos autores.

As entrevistas foram feitas com base em um roteiro com oito perguntas, por meio do qual se procurava entender como esses profissionais, envolvidos diretamente nas atividades de captação e seleção de futuros empregados, conduzem esse processo com vistas a atrair e recrutar os profissionais considerados adequados à empresa. O Quadro 2 apresenta o roteiro utilizado: 


\section{Quadro 2}

\section{Roteiro de entrevista}

1. Você considera a sua empresa como uma empresa de alta performance? Por quê? Julga que isso seja um fator de atratividade de bons profissionais? Por quê?

2. Qual é o perfil de profissional que você procura ao iniciar um recrutamento?

3. A que fatores você atribui a atração do candidato para a sua empresa?

4. Quais são os principais diferenciais da empresa para atração de candidatos, isto é, o que é oferecido a ele que desperta o interesse desse perfil de candidato?

5. Quando você encontra um candidato que considera "perfeito", quais os argumentos que usa para seduzi-lo?

6. O que o candidato pode esperar da empresa? E o que não pode?

7. Como tende a ser a rotina de trabalho do profissional? Você comenta essa rotina ao apresentar a vaga ao candidato?

8. Você costuma comentar, na entrevista, fatores como ambiente de trabalho, qualidade de vida e outros aspectos intangíveis ao apresentar a empresa? Por quê?

Fonte: elaborado pelos autores.

As entrevistas foram gravadas e transcritas na íntegra, de modo que se pudesse fazer uma análise completa do discurso dos entrevistados. As entrevistas cessaram quando os pesquisadores julgaram que ocorreu uma saturação nas categorias de significados, ou seja, quando não surgiram mais novos temas e categorias nas últimas entrevistas. A análise do conteúdo das entrevistas, valendo-se da lente teórica que nomeia os elementos constitutivos da razão instrumental, permitiu a construção, a posteriori, de categorias que identificaram a expressão de vários desses elementos nos discursos dos entrevistados. Essas categorias estruturam a análise apresentada a seguir.

\section{Atração de Funcionários para Empresas de Alta Performance: uma Apreciação Crítica aos Argumentos dos Profissionais de Recursos Humanos}

Os discursos, frutos das entrevistas realizadas com profissionais de recursos humanos para justificar a atratividade das empresas de alta performance, foram analisados à luz dos elementos constitutivos da razão instrumental, no intuito de avaliar o quanto esses discursos são permeados por essa racionalidade, bem como o de desvelar potenciais distorções comunicativas inerentes à interação promovida sob a égide do agir estratégico orientado, utilitariamente, ao êxito.

Entre os fatores de atração organizacional mencionados nas entrevistas, aqueles que apresentaram maior incidência foram: a promessa de crescimento acelerado; a aprendizagem contínua via investimentos em treinamento; e a meritocracia. Apesar do destaque dado pelos entrevistados a esses fatores, considerados positivos e capazes de atrair profissionais qualificados às organizações em foco, alguns aspectos negativos característicos da dinâmica de trabalho nessas organizações não foram ignorados, quais sejam: a intensificação do trabalho, a necessidade de sacrifício da vida pessoal e o clima excessivamente competitivo. A seguir, cada um desses fatores é abordado de forma mais detalhada. 


\section{A promessa do crescimento (com as próprias pernas)}

A menção ao crescimento rápido, como fator de atração de novos profissionais, é recorrente nos depoimentos dos entrevistados. A potencialidade de uma carreira meteórica é associada ao sucesso individual, entendido como o alcance de estágios e situações considerados vitoriosos em face de processos competitivos numa sociedade capitalista (SERVA, 1997). O relato seguinte ilustra essa expectativa:

Outra coisa importante que faz com que as pessoas sejam retidas dentro da empresa é o plano de carreira, que é muito acelerado em comparação a outras empresas comuns. Enquanto [em] empresas [dos ramos de] mineração e óleo e gás o funcionário sai de um cargo de analista júnior para analista sênior num prazo de 5 a 10 anos, aqui na empresa todo ano nós recebemos um cargo diferente, sendo reconhecido por isso. No máximo em três anos me torno consultora e em quatro anos já viro gerente e assim por diante. (Entrevistada $3)$.

A promessa de uma carreira acelerada talvez seja o principal atrativo dessas empresas, e tem forte apelo entre os mais jovens, que optam por ingressar nessas organizações na esperança de se destacarem e ascenderem rapidamente. Há de se realçar, no entanto, que a estrutura acelerada de carreira tende a priorizar uns em detrimento de outros, evidenciando uma seleção natural na qual as armas oferecidas, apesar de serem propugnadas como iguais para todos, reforçam a responsabilização individual tanto pelo sucesso quanto pelo fracasso. O preço a ser pago, subjacente à promessa de ascensão rápida, é alto, pois implica empenho e iniciativa individuais:

As oportunidades e o espaço para crescer vão existir, e nós jogamos essa responsabilidade muito na mão deles: você vai criar seu espaço, você vai criar seu plano de carreira, isso é o grande atrativo. (Entrevistada 1).

Ressalta-se, em contraposição à fala anterior, que o discurso corporativo, ao reforçar o agir individual desatrelado da consideração da perspectiva do outro, impossibilita o desenvolvimento da competência comunicativa dos agentes, minimizando, assim, suas possibilidades de questionamento acerca das pretensões de validade sistêmicas que sustentam a linguagem corporativa/institucional. Consequentemente, estabelecem-se processos de comunicação sistematicamente distorcidos, visando à reprodução de sistemas de poder, linguagem e trabalho (FORESTER, 1994).

\section{A organização como "escola": a reprodução do discurso corporativo}

A promessa de aprendizagem contínua também surge como um aspecto valorizado pelos profissionais que atuam nas organizações objeto de análise, a julgar pela ênfase que os respondentes lhe atribuem. Ressalva-se, ainda, que a disseminação de práticas comunicativas orientadas ao enredamento dos membros das organizações ao seu discurso é amplamente utilizada, resultando no deslocamento de papéis outrora reservados à esfera do mundo da vida - a exemplo da educação - para a dimensão corporativa. O relato seguinte reforça a associação da empresa à "escola":

[...] a possibilidade de aprender e se desenvolver é um grande diferencial, até porque muitos falam do fato desta empresa ser uma escola, a pessoa passa por diferentes áreas, vê o negócio como um todo. (Entrevistada 1). 
Desta forma, as intensas pressões e cobranças vivenciadas pelos integrantes das organizações de alta performance parecem ser compensadas pelo aprendizado específico por elas proporcionado, e conforme seus interesses. O termo "escola" - para se referir a estas organizações - é recorrente no discurso dos entrevistados, sugerindo que os esforços feitos pelos trabalhadores nestas organizações é parte de um processo de aprendizagem, quiçá um rito de passagem. Todavia uma contradição surge da função educacional atribuída a tais empresas, uma vez que, ao promoverem a intensificação do trabalho, acabam por obstar, ainda que parcialmente, o devido desenvolvimento acadêmico daqueles profissionais jovens recémcontratados, que, por muitas vezes, têm de conjugar trabalho e formação acadêmica:

[...] [a empresa] atrai bastante os estudantes porque, além de ser uma escola de desenvolvimento, uma pessoa que entra sem experiência nenhuma aprende, desenvolve, cresce, tem planos de carreira. [...] A vida [do trainee] é como [a de] um profissional normal, trabalha oito horas ou até mais [...]. O trabalho é árduo mesmo, às vezes não temos nem feriado ou final de semana. (Entrevistada 5).

A impropriedade da assunção das "corporações enquanto escolas" decorre do fato de que "[...] a empresa capitalista e a administração, ao se configurarem em unidades sistemicamente independentes do mundo da vida e, portanto, no interior de subsistemas isentos de conteúdo normativo" (HABERMAS, 2012b, p. 311), reforçam, por meio de suas "ações educativas", a reprodução material do subsistema econômico. Ainda que o sistema educacional seja um dos alvos da colonização do subsistema econômico, não há como confundir a aprendizagem adquirida nas instituições educacionais, cujo locus é o mundo da vida, com aquela práticoteórica transmitida no interior das organizações e, portanto, situada no subsistema econômico. Tais sistemas ou mundos são, no entendimento de Habermas, independentes e orientados por mecanismos de integração diversos, a ação comunicativa e o dinheiro respectivamente.

Desse modo, pode-se argumentar que a referida associação, evidenciada na declaração da entrevistada, é fundamentalmente um recurso retórico mobilizado pelos agentes e tem como missão atrair novos funcionários às organizações que representam.

\section{Meritocracia (ou darwinismo social?)}

A ênfase na meritocracia, refletida no foco constante em resultados individuais, é um traço característico da organização moderna: busca-se a superação do indivíduo na consecução de níveis exitosos de entregas, em um ambiente altamente competitivo e, por vezes, pouco salutar. No caso das empresas objeto deste estudo, o discurso de valorização da meritocracia é proferido por todos os entrevistados, pois, subjacente à excelência implícita no conceito de alta performance está a excelência de seus integrantes. Os depoimentos dos entrevistados apontam a meritocracia como um atrativo para os candidatos que buscam não apenas uma vaga nessas organizações, mas também o pertencimento a um coletivo que se projeta como vitorioso:

A [nossa] empresa é de alta performance porque é uma empresa focada em resultado e metas. A gente tem curva forçada. A gente exige que o funcionário sempre seja excelente, senão ele não consegue permanecer aqui. Somos medidos por performance e indicadores [...] Todo o reconhecimento é feito por mérito, nunca por tempo de casa ou cargo. Tudo é meritocracia. (Entrevistada 4).

A associação comum, no ambiente corporativo, do desempenho individual à premiação na forma de bônus ou congêneres, em especial nas empresas de alta performance, denota a associação do desempenho à performance individual superior, elemento central da racionalidade instrumental (SERVA, 1997). Assim, as 
recompensas financeiras valem não somente pelo que representam em termos de ganhos materiais, mas também por seu efeito simbólico, ou seja, uma performance exitosa:

O outro [fator que desperta interesse] é o dinheiro: o bônus, as premiações, a participação nos lucros e resultados. No geral a pessoa acaba fazendo cerca de $80 \%$ da remuneração em bônus, isso sem dúvida é um atrativo. Pessoas jovens com a possibilidade de fazer muito mais dinheiro do que lá fora. (Entrevistada 1).

Torna-se, assim, improvável que "[...] os atores participantes comportem-se cooperativamente e tentem colocar seus planos (no horizonte de um mundo da vida compartilhado) em sintonia uns com os outros na base de interpretações comuns da situação" (HABERMAS, 2002b, p. 129).

Outro aspecto a ser destacado é que, ao se reificar o mérito como uma construção individual, acaba-se por desconsiderar as diferentes histórias de vida dos sujeitos e, consequentemente, o fato de que eventuais desigualdades sociais expressas, sobretudo, em termos de diferentes níveis de capital cultural e econômico acumulados, possam influenciar suas trajetórias futuras (LEMOS, DUBEUX e ROCHA-PINTO, 2014). Em suma, o termo "mérito", conforme analisado aqui, é falho ao indicar que se toma como premissa fundamental a igualdade de oportunidades dos agentes, reificando, portanto, a agência em detrimento de coerções estruturais de toda espécie.

A própria dinâmica contingencial do pagamento de bônus ou demais remunerações, vinculada a um processo decisório do qual a maioria absoluta dos indivíduos nas organizações está alijada, aparece naturalizada no depoimento anterior, ilustrando como a dimensão do conflito entre os interesses organizacionais e de seus colaboradores é ressignificada em termos de um embate entre estes últimos. Consequentemente, o culto à potencialidade do ganho máximo individual, reproduzido socialmente, acaba por dissimular a tendência à redução dos ganhos fixos e dos direitos sociais conquistados ao longo de mais de um século de lutas travadas pelos trabalhadores.

\section{Alta performance com qualidade de vida?}

Aos aspectos apresentados como centrais à atratividade exercida pelas empresas de alta performance sobre seus funcionários, somam-se aqueles que se configuram como o "preço a ser pago" para aderir a esses sistemas e gozar dos "benefícios" proporcionados por essas organizações. A intensificação do trabalho é um desses aspectos; decorrente, em grande medida, da maximização dos recursos, tida como um dos imperativos da organização moderna e característica central da racionalidade instrumental:

A rotina de lá já é conhecida: é agressiva, é pressão o tempo inteiro, o resultado é entregue diariamente. Então, não é uma rotina tranquila. (Entrevistada 2).

Na busca da eficiência e eficácia máximas, as organizações buscam otimizar os seus "recursos", chegando ao limiar da não observação a requisitos legais tais como o cumprimento de carga horária, tudo justificado em nome de um discurso de comprometimento com a empresa e de potenciais ganhos superiores na forma de bônus:

O que as pessoas não podem esperar é qualidade de vida [...]. Comento porque é a mais pura verdade. A qualidade de vida é um dos motivos de saída dos empregados. As estruturas da empresa são muito enxutas e as pessoas acabam trabalhando doze horas por dia como algo normal e não algo esporádico. (Entrevistada 7). 
A perda de qualidade de vida decorrente da prática da intensificação do trabalho é assumida pelos entrevistados como uma consequência natural da inserção nessas organizações. O relato seguinte evidencia essa naturalização:

Falo que elas vão ter que abrir mão da vida pessoal, porque muitas das pessoas que a gente contrata ou são estagiários ou são estudantes. A vida pessoal será comprometida em função dos estudos e das responsabilidades que serão cobradas aqui na empresa. (Entrevistada 1).

A despeito de eventuais efeitos positivos da intensificação do trabalho para o indivíduo e para a organização, destacados na literatura (HUSELID, 1995; APPELBAUM, BAILEY e BERG, 2000; HARTOG e VERBURG, 2004; HUGHES, 2008), os trechos anteriores permitem associar à distensão da dimensão do trabalho na vida dos indivíduos, em especial nas empresas ditas de alta performance, uma retração da participação em outras esferas do mundo da vida tais como a familiar e a comunitária. Todavia, conforme destacado a priori, as pressões e cobranças enfrentadas por aqueles que desejam atuar nestas organizações, apesar de comprometerem sua qualidade de vida, seriam supostamente compensadas pelos ganhos expressos no "aprendizado" e na cultura meritocrática, que identifica, promove e premia os "melhores".

No entanto, parece ser alto o preço a ser pago por "vestir a camisa" das empresas de alta performance e, portanto, fazer parte da elite corporativa. Comparável a um cobertor curto, a camisa que veste uma esfera da vida deixa as demais descobertas, como a real presença do indivíduo em sua família e nas comunidades de pertença. À presença física opõe-se aquela instrumental, representada pelo que ou por quem o dinheiro pode comprar. Professores particulares, personal trainers, personal stylists, babás e objetos de desejo de todo tipo generalizam-se como substitutos daqueles ausentes por conta de uma dedicação extremada ao trabalho. Consequentemente, trocam-se ou eliminam-se os rostos das relações face a face tradicionais.

\section{A construção da cultura organizacional de alta performance}

Os discursos dos entrevistados atestam o esforço promovido pelas corporações no desenvolvimento de práticas de comunicação que a distorcem, como resultado,uma vez que burlam alguns dos requisitos de validade do ato de fala. A presença de altos executivos nas práticas motivacionais configura-se em um eficiente mecanismo de controle dos membros das organizações, dado que, por estarem no topo da hierarquia, as lideranças atuam de forma decisiva na construção dos significados a serem propagados internamente como expressão importante da cultura organizacional:

Nós temos apresentações onde o diretor executivo e o presidente falam de todos os resultados da empresa; isso é passado ao vivo para todos os shoppings do Brasil, temos noção dos resultados da empresa antes de o mercado saber. (Entrevistada 4).

A disseminação da cultura organizacional é vital ao comprometimento dos "colaboradores", ainda que conquistada pela prática reiterada de uma miríade de mecanismos de manipulação na interação comunicativa (VIZEU e CICMANEC, 2013). A importância da adesão à cultura corporativa pode ser ilustrada pelas seguintes falas:

Outro ponto importante é a cultura da empresa [...] muito forte, de perfil agressivo e com pessoas que realmente vestem a camisa [...]. Todo mundo que trabalha lá dentro tem orgulho de participar disto. Uma coisa que importa lá dentro é o perfil, e sua aderência à cultura. Então buscamos aquelas pessoas em que enxergamos que a cultura será de fácil acesso. (Entrevistada 2). 
Eu não posso ter pessoas que não acreditem na nossa cultura porque isso contamina a equipe. (Entrevistada1).

Além de sublinhar a relevância da cultura, esses discursos trazem à baila dois pontos-chave: (1) a homogeneização do perfil dos trabalhadores, no sentido da fácil aderência destes à ideologia corporativa, e (2) a naturalização do discurso corporativo.

A adesão a essa cultura de alta performance não evita, todavia, que o ambiente organizacional fique comprometido, nem tampouco garante a lealdade dos trabalhadores, haja vista a potencial alta rotatividade do quadro de pessoal:

A gente trabalha muito o reconhecimento. Nós temos um programa que é o de excelência em processos. $\mathrm{O}$ melhor processo de marketing ganha um troféu do presidente. Todo o reconhecimento é feito por mérito, nunca por tempo de casa ou cargo. Tudo é meritocracia [...]. Nosso turn over é alto, 30\%. (Entrevistada 4).

O reconhecimento, por parte dos entrevistados, do comprometimento do ambiente organizacional, associado, eventualmente, à sua supressão no processo de seleção de pessoal, conforme depoimento da Entrevistada 7 , configura uma ação consciente veladamente orientada ao agir estratégico. Transgridem-se, portanto, as pretensões de validade da verdade proposicional e da sinceridade, necessárias ao estabelecimento de uma ação comunicativa. Quando questionada se costumava comentar, na entrevista, fatores como ambiente de trabalho, qualidade de vida e outros aspectos intangíveis ao apresentar a empresa, a entrevistada respondeu nos seguintes termos:

Não. [Porque] na realidade o clima era de extrema competitividade e pouco saudável. (Entrevistada 7).

Concluindo, percebe-se que o quadro de referência no qual se situam os discursos analisados remete àquele da razão instrumental, no qual o trabalhador tem sua subjetividade ao menos parcialmente aprisionada como condição para a emergência de um outro docilizado e propício à moldagem dos ditames da ideologia capitalista. Suprime-se assim uma diversidade de vozes em nome da unidade de uma razão monológica.

\section{Considerações Finais}

Os discursos dos profissionais de recursos humanos analisados neste trabalho evidenciam o fenômeno da distorção comunicativa de forma a promover, mesmo que parcialmente, a homogeneização do discurso organizacional, legitimador do status quo, haja vista que o processo de introjeção dos valores organizacionais, em última instância, acarreta um mecanismo de autocontrole ajustado segundo os ditames corporativos.

Quando verbalizam os argumentos utilizados para atrair futuros integrantes às organizações as quais representam, tais profissionais desvelam o discurso corporativo que tende a preponderar não só nas organizações nas quais atuam, mas também em outras congêneres. O discurso que legitima as práticas típicas das empresas de alta performance busca imprimir um sentido positivo a uma cultura de trabalho que, mesmo aos olhos daqueles incumbidos de atrair para os quadros das empresas novos "colaboradores", insinua-se como eventualmente negativa. No reconhecimento do excesso de pressão, de curvas de desempenho "forçadas" e de longas jornadas de trabalho, em contrapartida ao crescimento rápido e ao aprendizado, os profissionais de recursos humanos talvez estejam tentando justificar para si mesmos as condições de trabalho adversas às quais são submetidos. 
Conforme ressaltado na análise, a presença da racionalidade instrumental nesses discursos evidencia a colonização do mundo da vida pelo agir orientado ao êxito, que reverbera nas organizações. Pode-se, desse modo, vislumbrar na hegemonia dessa racionalidade a manifestação desta patologia moderna, manifestada no contexto deste artigo, no constrangimento do homem pela lógica do mercado, expressa nos depoimentos que apontam para a naturalização do fato de as pessoas não poderem "esperar qualidade de vida" nas organizações nas quais estão inseridas.

Como representantes das organizações, os profissionais de recursos humanos entrevistados não parecem enxergar esse fato como um problema, seja para eles próprios, seja para os futuros ingressantes. Segundo Freitag (1993, p. 29), pode-se entender a naturalização desse fato como efeito da lógica estabelecida pelo mercado, que, ao submeter o homem aos "[...] mecanismos de integração dinheiro e poder, exclui de sua prática princípios de verdade, moralidade e expressividade". Todavia, cabe destacar que, ao mesmo tempo em que naturalizam a dinâmica de trabalho que impera nestas empresas, estes indivíduos deixam escapar, nas entrelinhas de suas falas, um desconforto frente a esta dinâmica quando reconhecem o fato de omitirem, nas entrevistas de seleção, alguns aspectos do cotidiano das empresas, como a excessiva competição mencionada por uma das entrevistadas, ou seja, reconhecem tratar-se de algo "pouco saudável".

As visíveis distorções presentes na realidade retratada são atribuídas não apenas à autonomização da economia em relação ao mundo da vida, mas também à colonização de esferas sociais outras tais como a família, as comunidades de pertença e a cultura, destacando-se, neste último caso, o papel fundamental da educação e da mídia como instâncias reprodutoras da lógica dominante.

Na tentativa de dar conta dessa realidade, os estudos críticos em organizações opõem-se, frontalmente, à teoria vigente, assumida como inadequada para a análise e o entendimento da vida social, dada sua abordagem pretensamente objetiva e supostamente neutra. A Teoria Crítica apresenta-se, antes de tudo, como ciência reflexiva, cujo um dos alvos de crítica é a razão instrumental em si (ADORNO e HORKEIMER, 2004), que atua como fator de impedimento à emancipação dos indivíduos em sociedade (TENÓRIO, 1998).

Em sua Teoria da Ação Comunicativa, Habermas (2012a; 2012b) propõe a construção de uma nova racionalidade, baseada na compreensão intersubjetiva de sujeitos livres. Na propositura de uma relação dialética entre as razões instrumental e comunicativa, apresenta, como regra geral, a precedência do todo sobre a parte ou da sociedade perante o indivíduo. Nesse sentido, a razão comunicativa é proposta como um rompimento com o quadro anterior, embasando uma teoria que foca um real desenvolvimento cognitivo dos indivíduos, por meio da aprendizagem compartilhada pelos atos de fala, de forma a promover sua igualdade e a liberdade ou, em outros termos, a sua emancipação.

Assim sendo, pode-se vislumbrar nessa racionalidade uma possível saída para a colonização do mundo da vida, que vem sendo a marca das sociedades industrializadas contemporâneas e que se reflete nos discursos analisados. Os depoimentos dos profissionais de recursos humanos entrevistados revelam que esses indivíduos findam por atuar como agentes reprodutores dessa racionalidade, na medida em que reverberam um discurso por ela permeado.

Todavia seria ingênuo imaginar que essa será uma saída fácil, para não dizer utópica: esses indivíduos endossam essa racionalidade por serem eles também alvo do proselitismo que promove argumentos e valores instrumentais como ideais a serem alcançados. A valorização e a naturalização desses argumentos, expressas nas falas dos entrevistados, sinalizam a presença quase que ubíqua da racionalidade instrumental na sociedade contemporânea - o que torna a promoção da emancipação societária um desafio de proporções extraordinárias em nosso tempo. 


\section{Referências}

ADORNO, T.; HORKHEIMER, M. Dialética do esclarecimento: fragmentos filosóficos. 2. ed. Rio de Janeiro: Editora Jorge Zahar, 2004.

ALLAN, C.; O’DONNELL, M.; PEETZ, D. Three Dimensions of Labour Utilisation: Job Broadening, Employment Insecurity and Work Intensification. Current Research in Industrial Relations, v. 1, p. 12-24, 1999.

APPELBAUM, E.; BAILEY, T.; BERG, P. Manufacturing advantage: why high-performance systems pay off. New York: ILR Press, 2000.

BASHIR, M. et al. The effect of perception of existence of HPWS on employee's organizational commitment: A test of social exchange relationship and contingency perspective to implement HPWS in universities of China and Pakistan. Advances in Asian Social Science, v. 1, n. 1, p. 87-98, 2012.

BASTOS, A.; BORGES-ANDRADE, J. Comprometimento com o trabalho: padrões em diferentes contextos organizacionais. Rev. de Adm. de Empresas, v. 42, n. 2, p. 1-11, 2002.

BÖCKERMAN, P.; BRYSON, A.; LMAKUNNAS, P. Does high involvement management improve worker wellbeing? Journal of Economic Behavior \& Organization, v. 84, n. 2, p. 660-680, 2011.

BURREL, G. Modernism, Postmodernism and Organizational Analysis 4: The Contribution of Jürgen Habermas. Organization Studies, v. 15, n. 1, p. 1-45, 1994.

BURREL, G.; MORGAN, G. Sociological paradigms and organizational analysis: elements of the sociology of corporate life. 13. ed. Barlington: Ashgate, 2005.

BUTLER, P. et al. High performance management: a literature review. Learning as Work Research Paper, No. 1. Learning as work: teaching and learning processes in the contemporary work organisation. Leicester: CLMS, University of Leicester. 2004

CANÇADO, A. C.; TENÓRIO, F. G.; PEREIRA, J. R. Gestão social: reflexões teóricas e conceituais. Cad. EBAPE.BR, v. 9, n. 3, p. 681-687, 2011.

CAÑIBANO, A. Exploring the negative outcomes of flexible work arrangements. The case of a consultancy firm in Spain. Journal of Management, v. 31, n. 4, p. 622-640, 2011.

CARR, A. Critical theory and the management of change in organizations. Journal of Organizational Change Management, v. 13, n. 3, p. 208- 220, 2000.

CHI, N.-W.; LIN, C. Y.-Y. Beyond the high-performance paradigm: exploring the curvilinear relationship between high-performance work systems and organizational performance in taiwanese manufacturing firms. British Journal of Industrial Relations, v. 49, n. 3, p. 486-514, 2011.

DAL ROSSO, S. Mais Trabalho. São Paulo: Editora Boitempo, 2008.

DATTA, D. K.; GUTHRIE, J. P.; WRIGHT, P. M. Human resource management and labor productivity: does industry matter? Academy of Management Journal, v. 48, n. 1, p. 135-145, 2005.

DOMINGUES, J. M. Teorias sociológicas no século XX. 2. ed. Rio de Janeiro: Civilização Brasileira, 2004.

FRANÇA-FILHO, G. A via sustentável-solidária no desenvolvimento local. Organizações e Sociedade, v. 15, n. 45, p. 219- 232, 2008.

FORESTER, J. Teoria Crítica e Análise Organizacional. Plural, São Paulo, v. 1, p. 131-148, 1994. 
FREITAG, B. Habermas e a Filosofia da Modernidade. Perspectivas, São Paulo, v. 16, p. 23-45, 1993.

GREEN, F. Why has work effort become more intense? Conjectures and evidence about effort-biased technical change and other stories. University of Kent, Department of Economics, 2000. Disponível em <https://ideas.repec.org/p/ukc/ukcedp>. Acesso em 02 de dezembro de 2014.

GREEN, F. It's been a hard day's night: the concentration and intensification of work in late 20th century britain. British Journal of Industrial Relations, v. 39, n. 1, p. 53-80, 2001.

GREEN, F. Work intensification, discretion, and the decline in well-being at work. Eastern Economic Journal, v. 30, n. 4, p. 615-625, 2004.

GREEN, F.; MCINTOSH, S. The intensification of work in Europe. Labour Economics, v. 8, n. 2, p. 291-308, 2001

GRIMES, A. J. Critical Theory and Organizational Theory: a primer. Journal of Organizational Change Management, v. 5, n. 1, p. 26-30, 1992.

GUERREIRO RAMOS, A. A nova ciência das organizações: uma reconceituação da riqueza das nações. 2. 'ed. Rio de Janeiro: Editora da Fundação Getulio Vargas, 1981.

HABERMAS, J. O Discurso filosófico da modernidade. São Paulo: Editora Martins Fontes, 2002.

HABERMAS, J. Teoria do agir comunicativo: racionalidade da ação e racionalização social. São Paulo: Editora Martins Fontes, 2012a. v. 1.

HABERMAS, J. Teoria do Agir Comunicativo: Sobre a Crítica da Razão Funcionalista. São Paulo: Editora Martins Fontes, 2012b. v. 2.

HARTOG, D. N.; VERBURG, R. M. High performance work systems, organisational culture and firm effectiveness. Human Resource Management Journal, v. 14, n. 1, p. 55-78, 2004.

HEWLETT, S.; LUCE, C. Extreme jobs the dangerous allure of the 70-hour workweek. Harvard Business Review, v. 86, n. 12, p. 49-59, dec. 2006.

HUGHES, J. The high-performance paradigm: a review and evaluation. Learning as Work Research Paper, n. 16. Cardiff: Cardiff School of Social Sciences, Cardiff University, 2008.

HULST, M; VELDHOVEN, M; BECKERS, D. Overtime and need for recovery in relations to job demands and job control. Journal of Occupational Health, v. 48, n. 1, p. 11-19, 2006.

HUSELID, M. A. The impact of human resource management practices on turnover, productivity, and corporate financial performance. Academy of Management Journal, v. 38, n. 3, p. 635-672, 1995.

JAY, M. A Imaginação Dialética: História da Escola de Frankfurt e do Instituto de Pesquisas Sociais 1923-1950. Rio de Janeiro: Editora Contraponto, 2008.

KEHOE, R.; WRIGHT, P. The Impact of High-Performance Human Resource Practices on Employees' Attitudes and Behaviors. Journal of Management, v. 39, n. 2, p. 366-391, 2013.

KELLNER, D. Critical Theory, Marxism and Modernity. Maryland: The Jonhs Hopkins University Press, 1992.

LEE, J.; BANG, H. High performance work systems, person-organization fit and organizational outcomes. Journal of Business Administration Research, v. 1, n. 2, p. 129-138, 2012.

LEMOS, A. H. C.; DUBEUX, V. J. C.; ROCHA-PINTO, S. R. Educação superior, inserção profissional e origem social: limites e possibilidades. Sociedade, Contabilidade e Gestão, v. 9, n. 1, p. 48-64, jan./abr. 2014. 
LORENZO, R. A. As ações afirmativas para afrodescendentes articuladas a partir de parcerias intersetoriais: uma análise argumentativa do caso Geração XXI. Organizações e Sociedade, v. 19, n. 63, p. 697-713, 2012.

MACKY, K; BOXALL, P. High-Involviment work processes, work intensification and employee well-being: a study of New Zealand worker experiences. Asia Pacific Journal of Human Resources, v. 46, n. 1, p. 38-55, 2008.

RAMSEY, H.; SCHOLARIOS, D.; HARLEY, B. Employees and high-performance work systems: testing inside the black box. British Journal of Industrial Relations, v. 38, n. 4, p. 501-531, 2000.

SERVA, M. Abordagem substantiva e ação comunicativa: uma complementaridade proveitosa para a teoria das organizações. Rev. Adm. Pública, v. 31, n. 2, p. 108-134, 1997.

SPARHAM, E.; SUNG, J. High performance work practices — work intensification or 'win-win'? Centre for Labour Market Studies. Working Paper 50. Leicester: University of Leicester, 2007.

STEFFY, B.; GRIMES, A. A critical theory of organization science. Academy of Management Review, v. 11, n. 2, p. 322-336, 1986.

SWARNALATHA, C.; PRASANNA, T. S. Leveraging employee engagement for competitive advantage: HR's strategic role. Global Journal of Commerce \& Management Perspective, v. 2, n. 1, p. 1-6, 2013.

TENÓRIO, F. G. Gestão Social: uma perspectiva conceitual. Rev. Adm. Pública, v. 32, n. 5, p. 7-23, 1998.

TOPAL, C. The construction of general public interest: risk, legitimacy, and power in a public hearing. Organization Studies, v. 30, n. 2, p. 277-300, 2009.

TOWNLEY, B.; COOPER, D.; OAKES, L. Performance Measures and the Rationalization of Organizations. Organization Studies, v. 24, n. 7, p. 1045-1071, 2003.

VIEIRA, M.; CALDAS, M. Teoria Crítica e Pós-Modernismo: principais alternativas à hegemonia funcionalista. RAE, v. 46, n. 1, p. 59-70, 2006.

VIZEU, F. Ação Comunicativa e Estudos Organizacionais. Rev. Adm. de Empresas, v. 45, n. 4, p. 10-21, 2005.

VIZEU, F. Racionalidade Administrativa e Distorção Comunicativa nas Organizações Contemporâneas. In: ENCONTRO DA ASSOCIAÇÃO NACIONAL DE PÓS-GRADUAÇÃO E PESQUISA EM ADMINISTRAÇÃO, 33, 2009, Rio de Janeiro. Anais..., Rio de Janeiro: ANPAD, 2009.

VIZEU, F.; BIN. D. Democracia deliberativa: leitura crítica do caso CDES à luz da teoria do discurso. Rev. Adm. Pública, v. 42, n. 1, p. 83-108, 2008.

VIZEU, F.; CICMANEC, R. A música que encanta, o discurso que aprisiona: a distorção comunicativa em uma loja de departamentos. Cad. EBAPE.BR, v. 11, n. 1, p. 149-164, 2013.

WHITE, M. et al. High Performance Management Practices, Working hours and work-life balance. British journal of industrial Relations, v. 41, n. 2, p. 175-195, 2003.

WOOD, S.; MENEZES, L. M. High involvement management, high-performance work systems and well-being. The International Journal of Human Resource Management, v. 22, n. 7, p.1586-1610, 2011.

WOOD, S. et al. Enriched job design, high involvement management and organizational performance: the mediating roles of job satisfaction and well-being. Human Relations, v. 65, n. 4, p. 419-445, 2012. 